NOTAS

\title{
AUTONOMÍA Y BENEFICENCIA: EL PENSAMIENTO DE JOHN STUART MILL EN LA BIOÉTICA Joaquín Ocampo*
}

La Bioética, es una disciplina que se justifica por la existencia de una problemática en torno a algunos hechos de la vida en general y de la vida humana en particular y requiere, como toda disciplina, de un sistema conceptual propio que sirva como eje de análisis en el estudio de esa problemática. Como en toda disciplina que aborda alguna dimensión humana, al discurso de la Bioética confluyen diversas corrientes filosóficas a partir de las cuales, se trata de encontrar tanto la explicación de los problemas planteados como las soluciones más viables a cada uno de ellos. ${ }^{1}$

* Departamento de Historia y Filosofía de la Medicina, Facultad de Medicina, UNAM.

'Cfr. Organización Panamericana de la Salud, Bioética: Temas y perspectivas, 1990, Washington, D. C., OPS; J., Ocampo, Bioética. Una nueva disci-
Una de estas corrientes de pensamiento, es la del filósofo positivista inglés John Stuart Mill. La importancia de conocer y analizar su obra, no sólo radica en que algunas de sus tesis adquieren gran relevancia y actualidad en áreas como la sociología y la economía política en el discurso neoliberal, sino que, para algunos bioeticistas constituye el punto de partida para reflexiones de diversa naturaleza. ${ }^{2}$

plina, 1995, México, Gaceta del Colegio de Ciencias y Humanidades, año 5 , 10a. época, nº 194, UNAM, p. 4-5.

${ }^{2}$ Cfr. Organización Panamericana de la Salud, op. cit:; G. Sabine, Historia de la Teoría Política, 1991, México, FCE.; T. Engelhardt Jr., The Foundations of Bioethics, 1986, Nueva York, Oxford University Press; T.L. Beauchamp, J.F. Childress, Principles of Biomedical Ethics, 1989, 3a., New York, Oxford U.P. 
NOTAS

Un ejemplo de la influencia de este pensador, es el resultado de los trabajos desarrollados por la Comisión Nacional para la protección de los seres humanos en la investigación biomédica y conductual, organismo creado por el Congreso de Estados Unidos de América en 1977.

Dichos trabajos culminaron con la publicación en 1978 del documento "Principios éticos y lineamientos para la protección de los seres humanos", conocido también como Informe Belmont. Los principios allí establecidos son los de Autonomía, Beneficencia y Justicia. A partir de entonces, casi toda la Bioética los ha tomado como base, con pequeñas o grandes variantes asumiendo que las concepciones de los ciudadanos en el terreno moral, son diferantes entre sí $\mathrm{y}$, por tanto, sólo pueden generalizarse al conjunto de la sociedad aquellos valores éticos que la mayor parte de ella considera apropiados. ${ }^{3}$

Este trabajo tiene como objetivo presentar particularmente aquellos elementos del pensamiento de John Stuart Mill que, desde un punto de vista particular, han influido en el establecimiento de los principios de autonomía y beneficencia ya que, como señala Engelhardt, estos prin-

${ }^{3}$ Cfr. T.L. Beauchamp, L.B. Mc Cullough, Ética médica. Las responsabilidades de los médicos, 1989, Barcelona, Labor. cipios fundamentan y sintetizan dos perspectivas morales centrales, porque resumen un rango de problemas e intereses morales y además, porque dan las bases para la justificación de esos intereses en el ámbito de la atención a la salud. ${ }^{4}$

John Stuart Mill es el principal representante de la ${ }^{\circ}$ filosofía positivista y el liberalismo en la Inglaterra de la llamada era victoriana. Nació en 1806, hijo del economista y filósofo James Mill. Primogénito de una familia de ocho hermanos, desde muy pequeño fue sometido por su padre a una de las disciplinas de aprendizaje más rígidas de que se tenga memoria. Por sólo mencionar un hecho, a los cinco años ya leía a los clásicos griegos en la lengua original y a los latinos a los ocho. Esta actitud paterna, así como la relación sentimental, difícil y criticada que durante largo tiempo mantuvo con una dama de su época, con la que finalmente contrajo matrimonio, matizaron de alguna manera su modo de vivir y el contenido de su obra. ${ }^{5}$

En ella, es evidente la influencia de Epicuro así como de la tradición filosófica inglesa, desde el empirismo de Bacon hasta el utilitarismo de

${ }^{4}$ Cfr. T. Engelhardt Jr., op. cit.

${ }^{5}$ Cfr. F.A. Copleston, History of Philosophy, 1994, New York, Image Book; J.S. Mill, Autobiografia; 1986. Madrid, Alianza. 
Bentham y de su padre James Mill, incluyendo a Locke, Hume y Smith, además de la influencia de los pensadores de la Ilustración francesa y del positivismo comtiano, sin olvidar a César Beccaria, perteneciente a la Ilustración italiana y a Guillermo Von Humboldt, filósofo del Romanticismo alemán. Stuart Mill desempeñó algunos cargos en el gobierno de su país, luego de estudiar Jurisprudencia, y prácticamente toda su vida se dedicó al trabajo intelectual y a la vida pública, existiendo una gran coherencia entre su pensamiento $y$ sus acciones. ${ }^{6}$

El pensamiento ético de Mill, está plasmado en gran parte de lo que se considera su mejor obra, el ensayo Sobre la libertad publicado en 1859; en el libro VI de la obra Un sistema de lógica aparecido en 1843; en el ensayo sobre La sujeción de la mujeres eidtado en 1869 , y fundamentalmente en El Utilitarismo obra publicada en 1861.

En principio, para Stuart Mill la moral de los hombres no deriva más que de la sociedad humana. La moral es hecha, por así decirlo, por y para los hombres principalmente por aquellos que pertenecen a la clase dominante. Dice Mill: "En donde-

${ }^{6}$ Cfr. F.A. Copleston, op. cit.; J. S. Mill, Sobre la libertad, 1993, Madrid, Alianza; A. Mac Intyre, Historia de la ética, 1991, Barcelona, Paidós. quiera que hay una clase dominante, una gran parte de la moralidad del país emana de sus intereses y de sus sentimientos de clase superior. Así los gustos y disgustos de la sociedad o de alguna porción de ella, son los que principal y prácticamente, han determinado las reglas impuestas a la general observancia..."

A diferencia de muchas corrientes que consideran a la Ética como un área de reflexión dentro de la filosofía o una teoría de la moral, para Mill es un arte, dentro del concepto clásico griego de este término, es decir, como un conjunto de reglas o normas para realizar algo. "Todo lo que se expresa en reglas o preceptos, no en afirmaciones relativas a cuestiones fácticas, es arte. La ética o la moralidad es propiamente una parte del arte correspondiente a la ciencia de la naturaleza humana y la sociedad."8

Dice Mill que el método de la Ética es el del arte o la práctica en general. Al respecto, aborda un enfoque metodológico interesante, en el que relaciona a la ciencia con todo género de arte $y$, por ende, a la ciencia de la naturaleza humana y la sociedad con la Ética. Establece que una vez que cualquier arte define su objetivo central a lograr, la ciencia correspon-

${ }^{7}$ Cr. J. S. Mill, op. cit.

${ }^{8} \mathrm{Cfr}$. J. S. Mill, Un sistema de lógica, L. VI, en: El Utilitarismo, 1991, Madrid, Alianza. 


\section{NOTAS}

diente investiga sus causas y condiciones como fenómeno, para elaborar un teorema que incluye las circunstancias mediante las cuales, tal objetivo puede ser logrado. El arte retoma entonces dicho teorema y examina sus posibilidades de realización. Si es factible, se convierte en norma, regla o precepto. ${ }^{9}$

Sin embargo, "las reglas del arte no intentan comprender más condiciones que las que han de tenerse en cuenta en las circunstancias normales, siendo por consiguiente, siempre imperfectas" $" 10$ como ocurre en los problemas de la vida humana en donde uno no puede basarse sólo en las reglas científicas en que se fundamentan estas normas. Dice Mill: "Saber cuáles son las conti, encias prácticas que exigen la modificación de la regla, o que constituyen por completo excepciones a la misma, significa saber qué combinaciones de circunstancias obstaculizarían totalmente las consecuencias de tales leyes, lo cual sólo puede conocerse mediante la referencia a los fundamentos teóricos de la regla." " Por lo tanto todo aquel que se considere prudente, considerará la regla sólo como algo provisional.

Es a través de estas ideas que Mill deja claro, por una parte, la impor-
${ }^{9}$ Ibid.
${ }^{10}$ Ibid.
$"$ "lbid.

tancia que da a las circunstancias en que ocurren los actos humanos y la imperfectibilidad de las normas a las que a veces éstos se sujetan y, por otra, la noción de que todo arte relacionado con aspectos complejos de la vida humana, como es el caso de la Ética, se eleva en cierta forma por encima de la regla.

En este sentido, Mill no está de acuerdo con una ética normativa basada en máximas universales, de donde se deduzca el tipo de conducta que se deba de seguir para cada caso particular, porque no toma en cuenta el hecho de que alguna circunstancia particular puede impedir la consecución del fin propuesto, ya que la observancia de la norma puede entrar en conflicto con algún otro fin que, pudiera darse el caso, fuera más deseable, como sucedería, por ejemplo, en el caso en que un ciudadano $X$ tuviera que quitarle la vida a quien pretende asesinarlo. La norma dice 'no matarás', sin embargo, es evidente que el ciudadano $X$ tiene que actuar en defensa propia. De ahí que Mill piense que todo principio práctico debe basarse en fundamentos razonables y no en deducciones poco científicas. $^{12}$

Toda doctrina filosófica y ética, conlleva un concepto de ser humano.

${ }^{12}$ Cfr. J. S. Mill, Sobre la..., op. cit.; Un sistema.. op. cit.; El Utilitarismo, op. cit. 
El utilitarismo de John Stuart Mill no es la excepción, si bien a este concepto no lo desarrolla de manera particular, sí queda establecido a lo largo de todo su discurso.

Para el pensador inglés, el hombre es a la vez sensible y racional. Un ser que además de ser consciente de sí mismo y de tener la posibilidad de explicarse el mundo, también tiene deseos e intereses y por tanto la capacidad de sentir y de disfrutar o padecer todo lo que el mundo le ofrece. El hombre es un ser que se diferencia de los animales no sólo por su capacidad de pensar, crear e inventar el mundo, sino además, por su capacidad de elegiry de buscar principalmente fines, no solamente medios; se caracteriza por su capacidad para emprender acciones y ejercer su libertad para procurar el bien común y el propio. De ahí que el hombre sólo pueda lograr su bienestar a través de su libertad para elegir. Esto ratifica porqué Mill está en contra de una ética normativa que pretenda ser universal, que al no ir más allá del propio enunciado de sus reglas, pueda limitar las posibilidades de desarrollo de cada ser humano. La naturaleza humana, dice Mill, "no es una máquina que se construye según un modelo y dispuesta a hacer exactamente el trabajo que le sea prescrito, sino un árbol que necesita crecer y desarrollarse por todos lados, según las tendencias de sus fuerzas interiores, que hacen de él una cosa viva". ${ }^{13}$

En suma, el hombre es desde esta perspectiva, un ser que busca el bien propio y el de los demás a través de su libertad para elegir.

Es a partir de este concepto y de su noción de la moralidad como un arte que se basa en la ciencia de la naturaleza humana, considerando las circunstancias de la vida práctica del hombre, que el filósofo inglés establece una ética basada en un principio máximo y fin último, que es el principio de utilidad o de la mayor felicidad. Para el logro de este fin último, se tiene en la libertad de elección del sujeto, así como en su tendencia a procurar un beneficio para sí mismo y para los demás, el germen de lo que en la Bioética, con respecto a la relación médico-paciente o a la relación investigador-sujeto investigado, son los principios de autonomía y beneficencia, cuya observancia y no las reglas de una ética normativa, de acuerdo a las tesis de Mill, serían los medios para hacer realidad el principio de utilidad, es decir, la felicidad que tanto anhela el hombre. ${ }^{14}$

Dice Mill: "Cada arte presenta un primer principio único o una premi-

\footnotetext{
${ }^{13}$ Cfr. J. S. Mill, Sobre la..., op. cit.

${ }^{14} \mathrm{Cfr}$. J, S. Mill, El Utilitarismo, op.
} cit. 
NOTAS

sa mayor general, no tomado de la ciencia, a saber, aquel que enuncia el objeto que se persigue y afirma que constituye un objeto deseable. Las artes higiénicas y médicas presuponen, la una que la conservación de la salud, la otra que la curación de las enfermedades, son fines adecuados y deseables." (Estas proposiciones) "no afirman la existencia de nada, sino que aconsejan o recomiendan que algo sea" (no que deba ser como en la ética de normas). "El hecho afirmado por ellas es el de que la conducta recomendada produce en la mente del hablante el sentimiento de aprobación." 15

En este sentido, la búsqueda de la mayor felicidad no es una afirmación 'de la existencia de nada' ni un deber u obligación, simplemente una recomendación de que esto sea y que por sí sola nos conduce a su aprobación. Por otro lado, es incuestionable que, en términos generales, la autonomía del individuo es una condición fundamental para el logro de esa felicidad, todo ello manejado en términos de una recomendación basada en 'buenas razones' no en deberes.

Para entender de una manera un poco más amplia porqué los principios de autonomía y beneficencia son,

${ }^{15}$ Cfr. J.S. Mill, Un sistema.., op. cit.; El Utilitarismo, op. cit. en gran medida, la proyección actual del pensamiento de Mill en la Bioética, a partir de sus conceptos sobre la libertad del hombre y del significado de lo que es bueno para él, es necesario mencionar que con respecto al primero de ellos, el discurso de Mill no aborda el tema de la libertad desde una perspectiva metafísica en cuanto al significado de la libertad, por ejemplo, sino que en coherencia con su visión pragmática de la vida y su orientación filosófica positivista, lo que le preocupa es encontrar fórmulas para que la libertad del individuo no encuentre obstáculos para su desarrollo.

En la introducción de su ensayo Sobre la libertad, señala claramente y con la actitud de un visionario: "el objeto de este ensayo no es el Ilamado libre arbitrio, sino la libertad social o civil, es decir, la naturaleza y los límites del poder que puede ejercer legítimamente la sociedad sobre el individuo, cuestión que rara vez ha sido planteada (...) pero que influye profundamente en las controversias prácticas del siglo por su presencia latente y que, según todas las probabilidades, muy pronto se hará reconocer como la cuestión vital del porvenir". ${ }^{16}$

El concepto de libertad de John Stuart Mill va implícito en su con-

${ }^{16}$ Cfr. J. S. Mill, Sobre la.., op. cit 
cepto de hombre, es decir, la libertad es la plena realización del ser humano a través del ejercicio de la capacidad para elegir aquello que cada hombre desea y considera que es bueno para él.

Para el logro de la plena realización personal, Mill considera que la libertad humana comprende: la libertad de pensamiento y de credo político y religioso; la libertad de expresar y publicar sus propias opiniones; libertad en los gustos y determinación de las metas personales; libertad de acción según los deseos de cada quien sujetos a las consecuencias de los propios actos sin que lo impidan los demás en tanto no los perjudique "aunque ellos piensen que nuestra conducta es loca, perversa o equivocada" y desde luego, la libertad de reunión con fines benéficos. ${ }^{17}$ Sobre esta última condición, más adelante se comentará lo que Mill considera como benéfico desde su propia perspectiva ética conocida como Utilitarismo.

Para el pensador inglés, es evidente que la libertad del individuo no se logra con sólo desearla o considerarla como un derecho inalienable del sujeto, sino que, es necesario partir de algún principio que permita regular, en lo posible, las relaciones de la sociedad con el individuo y viceversa,

\section{${ }^{17}$ Ibid.}

dado el hecho de que el pleno ejercicio de la libertad de uno, puede interferir en el ejercicio de la libertad de los otros en la consecución de sus propios fines, generándose conflictos que pudieran evitarse o manejarse, si se partiera de un principio general que Mill enuncia de la siguiente manera:

"El único fin por el cual es justificable que la humanidad individual o colectivamente se entremeta en la libertad de acción de uno o cualquiera de sus miembros, es la propia protección. Que la única finalidad por la cual el poder puede, con pleno derecho, ser ejercido sobre un miembro de una comunidad civilizada contra su voluntad, es evitar que perjudique a los demás. Su propio bien físico o moral, no es justificación suficiente. Nadie puede ser obligado justificadamente a realizar o no realizar determinados actos, porque eso fuera mejor para él, porque lo haría feliz, porque, en opinión de los demás, hacerlo sería más acertado o más justo. Éstas son buenas razones para discutir, razonar o (persuadir a alguien) pero no obligarle o causarle algún perjuicio si obra de manera diferente. Para justificar esto sería preciso pensar que la conducta de que se trata (disuadir al sujeto) produciría un perjuicio a algún otro. La única parte de la conducta por la que (el sujeto) es responsable ante la socie- 
NOTAS

dad es la que se refiere a los demás. En la parte que le concierne meramente a él, su independencia es de derecho, absoluta. Sobre sí mismo, sobre su propio cuerpo y espíritu, el individuo es soberano." 18

Como puede observarse a partir de esta premisa, cada individuo puede ejercer su libertad como le plazca a condición de no afectar los derechos jurídicos de los demás y cada individuo tiene derecho a que nadie se inmiscuya en su vida privada. A este respecto Mill concuerda con Locke quien en su obra Ensayo sobre el gobierno civil, defiende el respeto a lo que él identifica como los derechos negativos del individuo, es decir, el derecho a que nadie interfiera en nuestra propia vida. ${ }^{19}$

Por otro lado, es evidente que el mencionado principio, señala que cada quien es responsable de su salud y de su vida. Dice Mill en otra parte de su discurso: "Cada uno es el guardián de su propia salud, sea física, mental o espiritual. La humanidad sale más gananciosa, consintiendo a cada cual vivir a su manera que no obligándole a vivir a la manera de los demás." ${ }^{20}$ Esta última consideración se relaciona con el pen-

${ }^{18} \mathrm{Ibid}$.

${ }^{19} \mathrm{Cfr}$. Organización Panamericana de la Salud, op. cit.

${ }^{20}$ Cfr. J. S. Mill, Sobre la..., op. cit. samiento político de Mill en cuanto que es necesario vigilar que el Estado promulgue leyes que respeten al máximo la autonomía del individuo ya que el Estado no puede legislar en contra del bienestar del sujeto aunque dicho bienestar signifique un daño para él, puesto que sería absurdo que el Estado intentara proteger al individuo de sí mismo. ${ }^{21}$

Una de las cuestiones que pueden surgir de lo hasta aquí expuesto es, que sí puede esperarse que todo ser humano por el hecho de serlo, esté en posibilidad de ejercer su autonomía, aún en ausencia de cualquier obstáculo. Al respecto el propio Mill da la respuesta señalando que tal ejercicio sólo es posible en seres humanos que están en la madurez de sus facultades, excluyendo a los niños y a aquellos jóvenes que no han alcanzado la mayoría de edad; "los discapacitados que deben ser protegidos de sus propios actos y del daño exterior, y aquellos estados atrasados de la sociedad en los que la misma raza puede ser considerada como en su minoría de edad". ${ }^{22}$ Esta última excepción para el ejercicio de la autonomía, llama la atención por la connotación racista que pudiera tener. Sin embargo, creo que tal consi-

${ }^{21}$ Cfr. G. Sabine, Historia..., op. cit.; J. S. Mill, Sobre la..., op. cit.

${ }^{22}$ J. S. Mill, ibid. 
deración pudiera explicarse porque en la época de Mill, se dudaba de que los aborígenes de las regiones de Oceanía, recién colonizadas por Inglaterra, fueran seres humanos. Más tarde fueron considerados miembros de sociedades a las que se identificó como 'primitivas', a partir de la creencia de que estaban en la fase incipiente de su desarrollo, no sólo cultural sino intelectual y que, por lo mismo, eran totalmente incapaces de asumir responsabilidades como los individuos de las sociedades europeas de aquel tiempo. ${ }^{23}$

En otro orden de ideas, para el ejercicio de la autonomía en términos de libertad para elegir, juega un papel importante según Mill, el grado de conocimiento que el sujeto tenga respecto al daño que pudiera recibir por hacer tal o cual elección. Esta consideración se ha introducido al discurso de la Bioética en el concepto de Consentimiento Informado que han desarrollado Engelhardt y otros bioeticistas. ${ }^{24}$

${ }^{23}$ Cfr. G. Lienhardt, Antropologia social, 1966, México, FCE.

${ }^{24} \mathrm{Cfr}$. T. Engelhardt Jr., The Foundations..., op. cit.; T. Engelhardt Jr., The search for a universal system of ethics: post-modern disappointments and contemporary possibilities, en: Kluwer Academic Publishers Ethical Problems in Dyalisis and Transplantation, London, 1992, p. 3-19; N.
Dice Mill: "Si un funcionario público u otra persona cualquiera, viera que alguien intentara atravesar un puente declarado inseguro y no tuviera tiempo de advertirle el peligro, podría cogerlo y hacerlo retroceder sin atentar por esto a su libertad, puesto que la libertad consiste en hacer lo que uno desea, y no desearía caer en el río. Sin embargo, cuando se trata de un daño posible, pero no seguro, nadie más que la persona interesada puede juzgar de la suficiencia de los motivos que puedan impulsarle a correr el riesgo; en este caso por tanto, mi opinión es que debe tan sólo ser advertido del peligro; $\sin$ impedir por la fuerza que se exponga a él."

Finalmente, con respecto al ejercicio de la autonomía, hay que señalar que Mill hace un análisis de ciertos hechos y circunstancias sociales que limitan el ejercicio de la libre elección, ya sea porque contribuyen a que el sujeto no tome conciencia de su capacidad de elegir o porque aún teniéndola, son obstáculos que dificultan de cualquier forma el libre desarrollo del individuo. Es así que critica a las dictaduras, a una opinión pública basada en gusto o sen-

Jecker, Aging and Etics, 1992, Totowa, N. J., Human Press; T. L. Beauchamp, J. F. Childress, Principles..., op. cit. ${ }^{25}$ Cfr. J. S. Mill, Sobre la..., op. cit. 


\section{NOTAS}

timentalismo, a la tradición y la costumbre y a la religión en muchos de sus aspectos. ${ }^{26}$

En párrafos anteriores se mencionó que toda doctrina filosófica tiene un concepto de 'lo bueno', es decir, de aquello a lo que el hombre debe aspirar y constituye su plena realización. En ese sentido, la ética de John Stuart Mill considera que lo bueno para el ser humano es lo útil, de ahí que a su filosofía moral se le dé el nombre de Utilitarismo. ${ }^{27}$

Cuando Mill habla de lo útil, no se refiere a la acepción común del término, es decir, a lo que sirve para algo o resuelve un problema de carácter material, sino a todo aquello que puede producir o conducir a una satisfacción de cualquier tipo no sólo a nivel sensorial sino a los más altos de la psique humana. Por tanto en Mill lo bueno es lo útil, lo que proporciona felicidad y placer.

Dada su concepción de la ética como un arte, menciona que cada arte tiene un primer principio único o una premisa mayor general, no tomado de la ciencia, que señala el objeto que se persigue, por considerarlo deseable. Ese principio es el de utilidad o de la máxima felicidad, al que considera el único criterio que determi-

\footnotetext{
${ }^{26} \mathrm{Ibid}$

${ }^{27}$ Cfr. A. Mac Intyre, op. cit.; J. S. Mill, El Utilitarismo, op. cit.
}

na la bondad o maldad absoluta o comparativa de fines u objetos de deseo, y por lo tanto el único criterio que debe normar todas nuestras acciones es el de la promoción de la felicidad como fin último. Sin embargo, señala también la existencia de fines intermedios como la nobleza, la justicia y la tolerancia que asimismo deben ser cultivados para la consecución de la felicidad.

Como se mencionó anteriormente, el placer o la felicidad para Mill no es solamente lo que se obtiene a nivel sensorial mediante la satisfacción de los apetitos corporales, idea que, por otra parte, fue muy criticada desde su época por considerar que el hombre puede aspirar a algo más. En su obra El Utilitarismo, hace una apología de sus ideas asumiendo una actitud contestataria ante sus críticos.

Cree que la utilidad, como criterio de lo bueno o lo correcto para el hombre, no se opone al placer ni se vincula totalmente con él. Su pensamiento va más allá al plantear que cuando se habla de placer, se hace alusión a algo más que el placer que puede experimentar un animal, porque comọ él mismo señala "los placeres de una bestia no satisfacen la concepción de felicidad de un ser humano. Los seres humanos poseen facultades más elevadas que los apetitos animales, y una vez que son conscientes de su existencia no conside- 
ran como felicidad nada que no incluya la gratificación de aquellas facultades". ${ }^{28}$ Mill está de acuerdo con quienes asignan a "los placeres del intelecto, de los sentimientos de la imaginación y de los sentimientos morales un valor mucho más elevado en cuanto placeres que a los de la pura sensación". ${ }^{29}$

En este sentido, si se considera que existen placeres inferiores y superiores, es obvio que el cultivo de estos últimos guarda una relación directa con el concepto de hombre que Mill tiene en mente, por corresponder a un cierto nivel de excelencia. Es aquí donde el filósofo inglés expresa su convencimiento, a partir de su propia experiencia, del gran valor que tiene la educación para el ser humano, porque es a través de cierto tipo de educación que el individuo puede preferir los placeres superiores sobre los inferiores, tratando de evitar el dolor o el sufrimiento de los demás, ya que la utilidad incluye no sólo la búsqueda de la felicidad sino además la prevención de la infelicidad propia y la ajena.

Dice Mill: "Es posible que todo ser humano debidamente educado sienta, en grados diversos, auténticos afectos privados y un interés sincero por el bien público. En un mun- do en el que hay tanto porqué interesarse, tanto qué disfrutar y también tanto que enmendar y mejorar, todo aquel que posea esta moderada proporción de requisitos morales e intelectuales puede disfrutar de una existencia que puede calificarse de envidiable", ${ }^{30}$ a menos que las fuentes de la felicidad se nieguen a través de leyes nocivas o por sometimiento a la voluntad de otros.

A través de todo lo anterior, el pensador deja ver, por un lado, que sin autonomía el sujeto no puede alcanzar la felicidad $y$, por otro, que una de las formas de alcanzarla es procurándola a otros, es decir, beneficiándolos.

Sin embargo, el procurar el bien a otros no es proporcionarles necesariamente el bien que uno quisiera para sí mismo, sino darles lo que para ellos es bueno, ya que de lo contrario estaríamos violando su autonomía. Así, en el acto de beneficiar a los otros procurándoles placeres superiores, en pleno ejercicio de la propia autonomía, se tiene la felicidad de todos. De ahí que pueda afirmarse que Mill comparte con Bentham la máxima de que hay que procurar "el mayor bien para el mayor número"31 y por otra parte, que la búsqueda de placer en Mill es más bien universalista, en el

\footnotetext{
${ }^{30} \mathrm{Ibid}$.

${ }^{31}$ Cfr. F.A. Copleston, op. cit.
} 
NOTAS

sentido de que todos lo involucrados pueden alcanzar la felicidad. ${ }^{32}$

Sin embargo, todo ello requiere de ciertas condiciones. En primer lugar, que los códigos y organizaciones sociales armonicen en lo posible, la felicidad o los intereses de cada individuo con los del conjunto, y en segundo, que la educación y la opinión pública "establezcan en la mente de todo individuo una asociación indisoluble entre su propia felicidad y el bien del conjunto"..$^{33}$ Es decir, que en el ejercicio de la autonomía de cada sujeto, para procurar el bien propio $y$ el ajeno, subyace un principio de solidaridad que Mill enfatiza en su discurso.

Es así que en los principios de autonomía y beneficencia de algunas orientaciones de la Bioética, es notoria la influencia del pensamiento de John Stuart Mill, a partir de su concepción de ser humano, de la libertad como derecho inalienable del hombre y del principio de utilidad.

De esta manera, se comprende porqué en el ámbito de la profesión médica, particularmente en la dinámica de la relación médico-paciente, desde la perspectiva utilitarista de Mill el paciente en ejercicio de su autonomía elegiría a su médico tratante; tendría la facultad de dar o no su con-

${ }^{32}$ Cfr. J. S. Mill, El Utilitarismo, op. cit. ${ }^{33} \mathrm{Ibid}$. sentimiento para participar en algún tipo de investigación médico-clínica o para someterse a algún procedimiento diagnóstico o terapéutico, previa información sobre los riesgos correspondientes o podría elegir el momento $y$ las circunstancias de su muerte, por señalar algunos ejemplos. ${ }^{34}$

El médico, por su parte, sería un benefactor, es decir, el procurador del bienestar del paciente en función de lo que éste considera su propio bien. De esta forma, las conductas éticas del médico serían aquéllas en donde, por ejemplo, proporcionara asistencia médica a una mujer que ha optado libremente por abortar porque considera que el embarazo y la maternidad limitan su realización personal en algún sentido. O la asistencia a un hombre que ha decidido quitarse la vida porque sólo de esa forma puede dar fin a los sufrimientos que ésta conlleva. O bien procurar la muerte de un paciente inconsciente $y$ sin ninguna posibilidad de reincorporarse a la vida social, a petición de sus familiares, es decir, el ejercicio de la eutanasia, término y concepto que introdujo Francis Bacon, uno de los empiristas ingleses que más influyeron en Mill. ${ }^{35}$

${ }^{34} \mathrm{Cfr}$. Organización Panamericana de la Salud, op. cit.; T. Engelhardt Jr., The Foundations..., op. cit.

${ }^{35} \mathrm{Cfr}$. Organización Panamericana de la Salud, op. cit.; F.A. Copleston, op. cit. 
Con relación a esta consideración, cabe mencionar el concepto que el filósofo inglés tiene del acto de morir. Al respecto quiero señalar que mientras que al cristiano le preocupa lo que pueda ocurrirle después de su muerte, en el sentido de que ignora si su alma llegará al paraíso o al infierno, $y$ al existencialista le angustia el hecho mismo de morir, de dejar de existir, de saber que inevitablemente llegará el momento en que tiene que desaparecer del mundo, a Stuart Mill le preocupan las circunstancias en que ocurra la muerte de cada persona, ya que no es lo mismo fallecer en condiciones dramáticas con el mayor sufrimiento y sin auxilio de nadie, que morir en la comodidad del hogar, con las menores molestias posibles y rodeado de los seres queridos.

Dice Mill: "El mero dejar de existir no es un mal para nadie. La idea que resulta aterradora es la que forja la imaginación al fabricar esta fantasía: la de imaginarnos como seres vivos sintiéndonos muertos al mismo tiempo. Lo doloroso de la muerte no es la muerte misma sino el acto de morir y sus lúgubres circunstancias, cosas todas ellas por las que también debe pasar el que cree en la inmortalidad. 136

\footnotetext{
${ }^{36}$ J.S. Mill, La utilidad de la religión, 1986, Madrid, Alianza.
}

Al pensamiento de John Stuart Mill se le han hecho numerosas observaciones desde los tiempos en que publicó sus obras hasta hoy en día. En la crítica destacan aquellos elementos en torno a la relación del individuo con la sociedad. Bradley, por ejemplo, afirma que Mill subestima la dependencia del individuo con la sociedad, privilegiando el egocentrismo por encima del compromiso y los deberes que cada hombre tiene con los demás aun en términos de sacrificio. De esta forma, en tanto que para Mill el suicidio sería válido, para otros filósofos es inmoral esta conducta asumiendo que un individuo no puede disponer de su existencia puesto que tiene un compromiso y una responsabilidad ante los otros, o bien, que siendo la vida el don de un ser supremo, sólo éste puede enajenarla.

En otros pensadores la crítica se ha orientado a su concepto de 'lo bueno' y a su consecuencia más importante, la de 'sociedad del bienestar'. Aranguren, quien ha abordado en profundidad el problema de la crisis moral de la sociedad contemporánea, plantea que ésta es una crisis entre aquellos principios que han caracterizado a la sociedad tradicional y los principios utilitaristas de 'la sociedad del bienestar', a la que cuestiona diciendo que ese bienestar se reduce finalmente a la posesión de bienes materiales y de una vida có- 
NOTAS

moda, libre de obligaciones y responsabilidades, que finalmente llevan al sujeto a una vida carente de sentido. Esto pudiera explicar porqué en algunos países donde priva el pensamiento utilitarista, el índice de suicidios es elevado.

Se ha cuestionado también a Mill su concepto de hombre abstracto, descontextualizado y ahistórico. Para él todo ser humano puede ejercer su libertad con sólo desearlo. Pasa por alto el hecho de que todo hombre es producto de su devenir dentro del marco de una cultura y de una sociedad determinada que también es el resultado de un proceso histórico.

Existen otras objeciones al pensamiento de John Stuart Mill, que por razones de espacio no es posible tratar aquí. Sirva este breve ensayo so96 bre su obra, para estimular los análisis que conduzcan a la aprobación de sus ideas o a su refutación. 